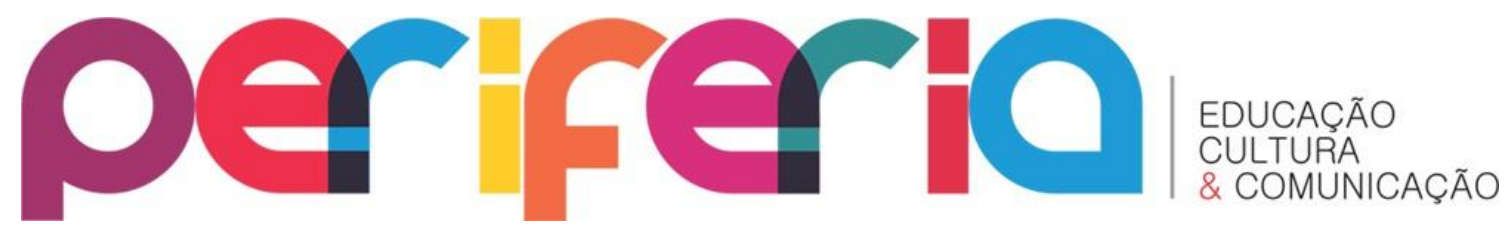

\title{
SOMOS USUÁRIOS DE SISTEMAS COMPUTACIONAIS OU SOMOS USADOS POR ELES?
}

Felipe da Silva Ponte de Carvalho ${ }^{1}$

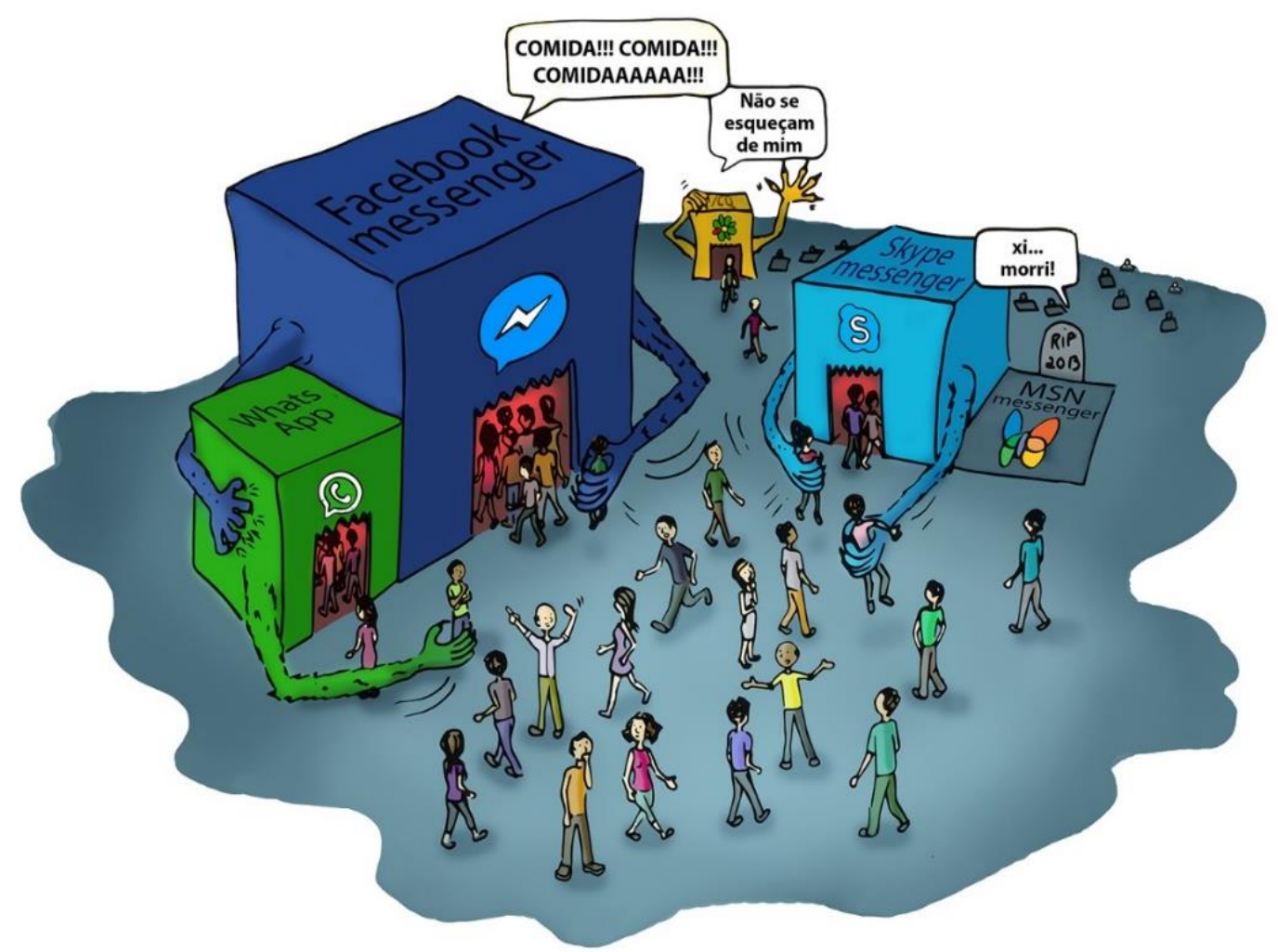

Fuks, 2014.

Figura 1 - Modelos dos meios de conversação da internet. Fonte: Calvão, Pimentel e

"Do email ao Facebook: uma perspectiva evolucionista sobre os meios de conversação da internet" (CALVÃO; PIMENTEL; FUKS, 2014a), escrito por pesquisadores em Sistemas de Informação, é um livro elaborado a partir de uma ideia simples, a de abandonar a perspectiva antropocêntrica em

\footnotetext{
${ }^{1}$ Doutorando pelo Programa de Pós-Graduação em Educação ProPed/Uerj. Membro do Grupo de Pesquisa Docência e Cibercultura (GPDOC). Bolsista FAPERJ. Orcid: http://orcid.org/0000-0001-7398$\underline{6171}$ E-mail: felipesilvaponte@gmail.com
} 


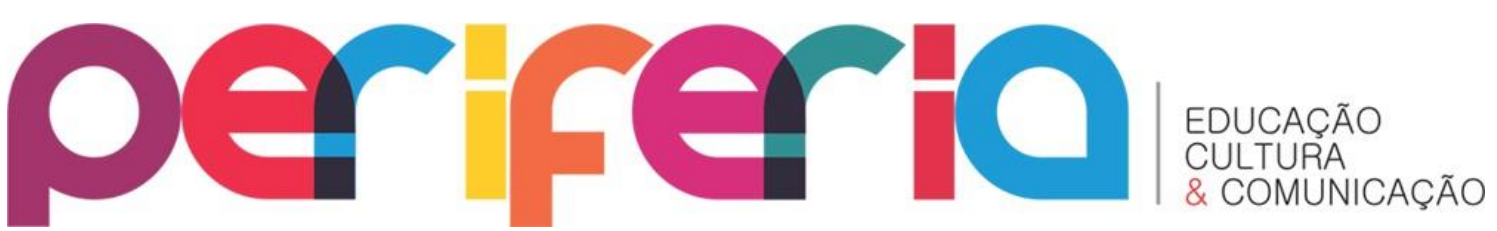

que nos consideramos usuários dos sistemas computacionais, para adotar a perspectiva dos sistemas como sendo eles os atores, e nós, humanos, os recursos disputados pelos sistemas. Nessa obra é estabelecida uma analogia entre a evolução dos sistemas computacionais de conversação e a evolução dos seres vivos: é como se os sistemas fossem os seres vivos; o ambiente onde os sistemas vivem é o momento sociotécnico-cultural; e os usuários são os recursos pelos quais competem os sistemas de uma determinada espécie. $\mathrm{Na}$ primeira ilustração desta resenha crítica, apresentada na Introdução do livro $^{2}$, são representados sistemas de mensageiro instantâneo disputando os usuários: o mensageiro do Facebook e o WhatsApp (comprado pelo Facebook) são os "mais adaptados" ao ambiente sociotecnico-cultural na década de 2010; sendo que os brasileiros usavam muito o MSN Messenger na segunda metade da década de 2000, que foi incorporado ao Skype Messenger e depois desativado (extinto); já o ICQ foi muito usado no final da década de 1990 e na primeira metade da década de 2000, depois praticamente ninguém mais usou embora tenha importância ainda hoje na Rússia.

Essa perspectiva, que antropomorfiza os sistemas computacionais, se fundamenta na noção do usuário como recurso disputado pelos sistemas que implementam um mesmo meio de conversação. A competição entre os sistemas ocorre porque, quando um usuário adota um sistema deixa de utilizar outros sistemas que implementam aquele mesmo meio. Por exemplo, quem usa o GMail para enviar e receber mensagens de email provavelmente não usa o Hotmail ou qualquer outro sistema para a troca de mensagens de email, pois os sistemas que implementam um mesmo meio de conversação têm o mesmo objetivo e assim basta o usuário adotar um deles para se comunicar. Como a quantidade de usuários é limitada, sistemas que implementam o mesmo meio competem entre si pelos usuários, formam um mercado e disputam para alcançar a maior participação naquele mercado. Por outro lado, sistemas que

\footnotetext{
2 Todas as imagens do livro estão licenciadas em Creative Commons e disponibilizadas na página do livro no facebook <https://www.facebook.com/meiosdeconversacao >
} 


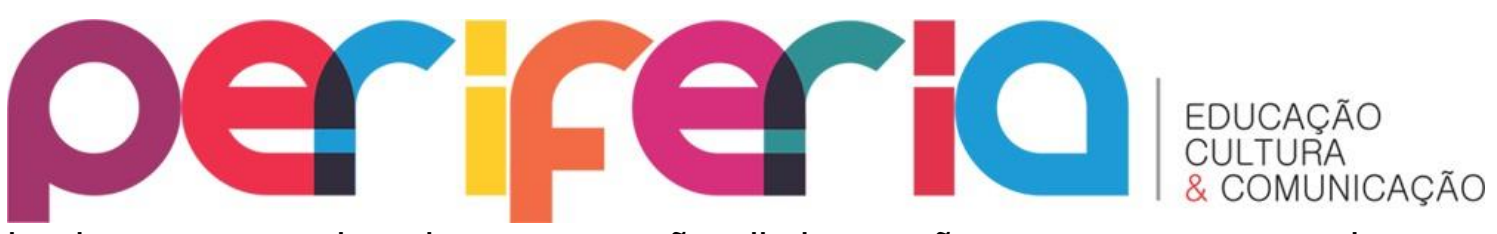

implementam meios de conversação distintos não competem entre si - por exemplo, uma mesma pessoa usa um sistema para enviar mensagem instantânea e pode utilizar outro sistema para realizar videochamada; a adoção de um sistema não impede a de outro sistema com finalidade distinta, portanto, esses sistemas não competem entre si pelos usuários.

Para analisar corretamente a ecologia dos sistemas e a competição entre eles (o ecossistema dos sistemas), é preciso considerar as diferenças que os autores estabeleceram sobre as noções de sistema computacional, serviço de conversação e meio de conversação. O Facebook, por exemplo, é um sistema computacional (de redes sociais); neste sistema estão disponíveis diversos serviços de comunicação, como o Feed de Notícias e Mensagens; cada um desses serviços implementa um meio de conversação (microblog, email, mensageiro, bate-papo, videochamada etc.). Enquanto o sistema e os serviços de conversação são implementações, os meios de conversação são abstrações, um modo específico de trocar mensagens. Por exemplo, um mensageiro instantâneo é um meio de conversação em que o usuário precisa ter uma lista de amigos cadastrados com os quais pode estabelecer uma conversa particular em tempo real com qualquer amigo que estiver online (conversação síncrona) - esse modo de conversar independe do sistema: Facebook, WhatsApp, Google Talk, MSN, ICQ, dentre outros sistemas disponibilizam um serviço de conversação que, com algumas variações de interface e funcionalidades, implementam este meio de conversação abstrato, o mensageiro instantâneo. Com esta diferenciação conceitual, os autores conseguem identificar que os sistemas que competem são aqueles que implementam um mesmo meio de conversação. Nem todos os sistemas de conversação competem entre si.

Dessa forma, a primeira questão que os autores tentam responder é: quais são os meios de conversação da internet? Para esboçar uma resposta, os autores ressaltam que é preciso considerar que o reconhecimento dos meios de conversação depende da cultura, sendo determinados histórica e 


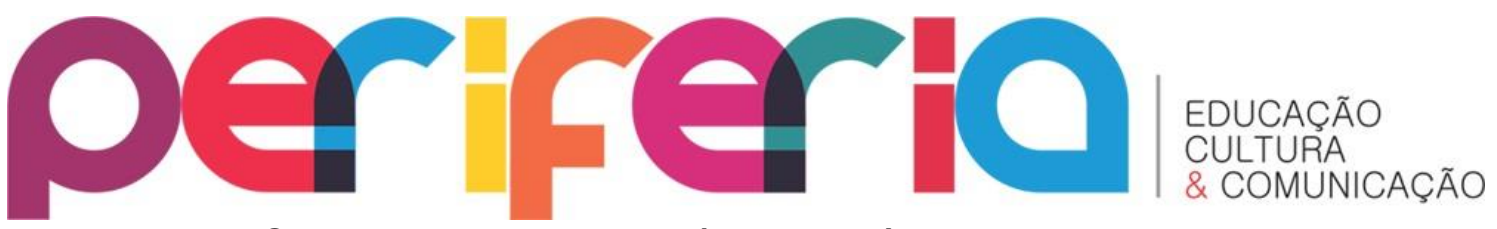

socialmente. Considerando a importância histórica e o reconhecimento social até o momento da publicação do livro, os autores identificaram os seguintes meios de conversação ilustrados no modelo a seguir e caracterizados no livro: email, lista de discussão, fórum de discussão, blog, microblog, mensageiro instantâneo, SMS, bate-papo, mensagens em grupo, videochamada, videoconferência, audiochamada e audioconferência.

\section{Modelo dos meios de conversação da internet}

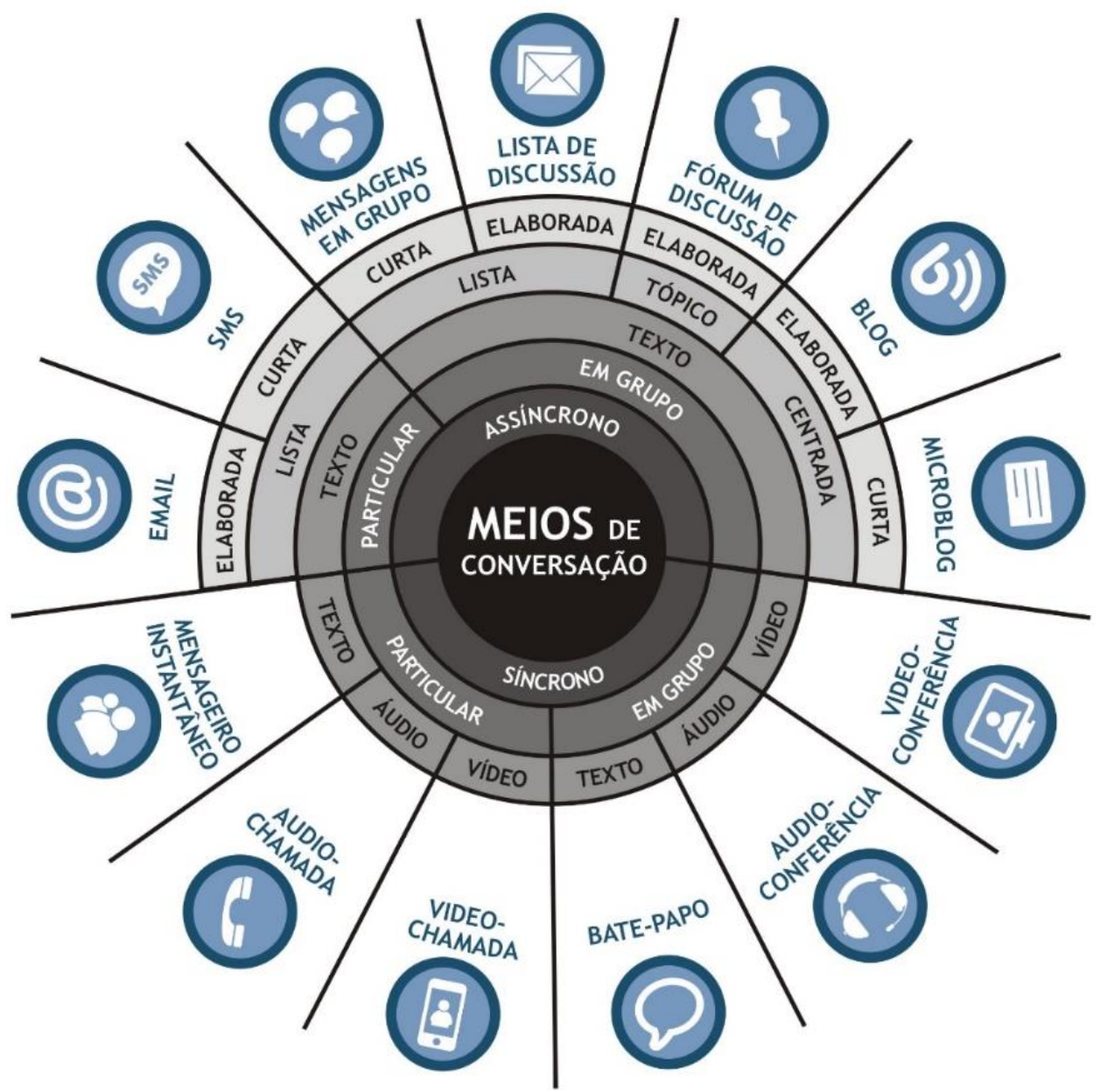

Figura 2 - Modelos dos meios de conversação da internet. Fonte: Calvão, Pimentel e Fuks, 2014.

Por um lado, dada a grande diversidade de serviços de conversação implementados nos incontáveis sistemas computacionais da atualidade e do passado, é surpreendente constatar que é possível abstrair em apenas 13 


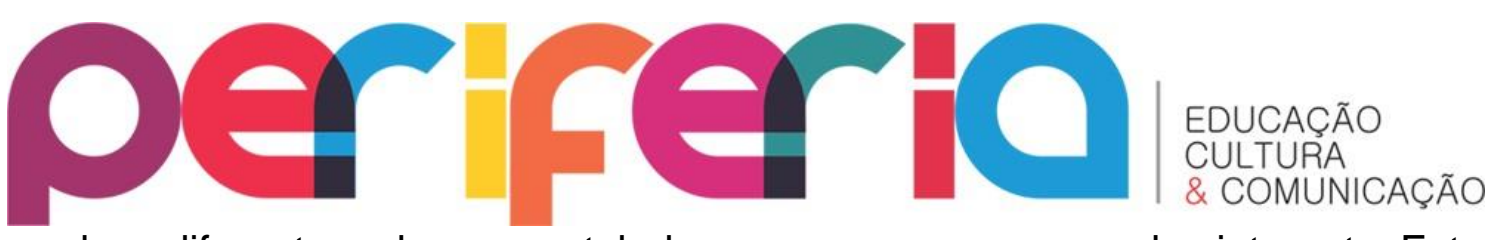

modos diferentes de se estabelecer uma conversa pela internet. Esta taxonomia (aos moldes da Taxonomia de Linnaeus dos seres vivos) nos apoia a compreender, identificar e diferenciar os meios de conversação e suas características peculiares. A partir desse estudo, é possível analisar o Facebook não como um único "meio de conversação e interação social", mas sim um sistema com diversos serviços que implementam diferentes meios de conversação, usados em diferentes momentos pelo usuário dependendo dos objetivos e da situação conversacional que precisam mobilizar na interação social.

A partir da analogia com a Biologia, os autores escreveram capítulos sobre Taxonomia, Evolução, Seleção e Ecossistema dos sistemas e meios de conversação da internet. Elaboraram conceitos, leis, modelos e métodos para tentar responder as questões clássicas da Biologia transpostas para este outro domínio: quais são os meios de conversação da internet, como evoluem e se diferenciam, por que alguns sistemas que implementam meios de conversação sobrevivem enquanto outros são extintos, como ocorre a competição entre eles pela disputa dos usuários? Os autores explicam:

\footnotetext{
Teorias sobre a evolução são propostas em diversas áreas do conhecimento para compreender como os objetos de estudo de cada área se relacionam entre si, e como e por que eles mudam com o tempo. A Biologia é a área de conhecimento que iniciou os estudos sobre a evolução, contudo, principalmente após a publicação das teorias de Darwin sobre a origem das espécies, em 1859, outras áreas como Sociologia (Spencer, 1860), Linguística (Schleicher, 1869) e Design (Steadman, 1979) também propuseram teorias, conceitos e modelos para explicar a evolução em suas áreas.
}

Este livro contribui para compreendermos os sistemas e os meios de conversação computacionais que dão suporte à cibercultura (CALVÃO; PIMENTEL; FUKS, 2014b), que é a cultura contemporânea mediada pelas tecnologias digitais em rede. Os autores enfatizam que os meios de conversação implementados em sistemas computacionais não surgiram neste século, não surgiram do nada nem de repente, muito menos por acaso; são 


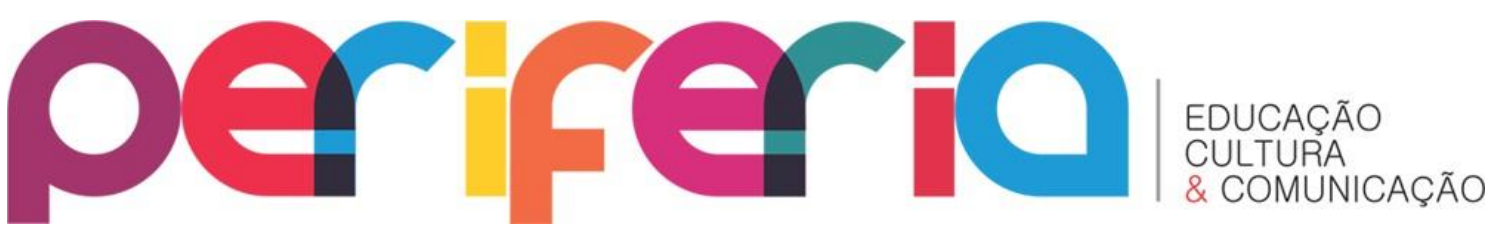

frutos de uma evolução. Essa perspectiva evolucionista contrapõe a visão criacionista na qual uma tecnologia surge como uma invenção, discurso que ainda impera no mercado comercial e muitas vezes na mídia. A perspectiva evolucionista é importante, inclusive, para evitar erros conceituais como: "fulano é o pai do email", sendo esta uma afirmação que reflete a visão criacionista; ou que os sistemas de redes sociais vão acabar com o email, quando de fato sequer competem entre si. Com essa perspectiva, os autores mudam nossa forma de analisar alguns dos fenômenos da cibercultura.

\section{REFEREÊNCIAS:}

CALVÃO, L. D.; PIMENTEL, M.; FUKS, H. Do email ao Facebook: uma perspectiva evolucionista sobre os meios de conversação da internet. Rio de Janeiro: UNIRIO, 2014a.

CALVÃO, L. D.; PIMENTEL, M.; FUKS, H. Sistemas e Meios de Conversação da Internet: a Evolução das Tecnologias que dão Suporte à Cibercultura. Anais do VIII Simpósio Nacional da ABCiber, 2014b. 